\title{
HBXIP activates the PPARס/NF-KB feedback loop resulting in cell proliferation
}

\author{
Qian Liu' ${ }^{1, *}$, Wenbin Lu, ${ }^{1, *}$, Chunxia Yang ${ }^{1}$, Yue Wang ${ }^{1}$, Wenjing Li $^{1}$, Ying Chu ${ }^{1}$, \\ Jianzhong Deng ${ }^{1}$, Yongzhong Hou ${ }^{2}$ and Jianhua Jin ${ }^{1}$ \\ ${ }^{1}$ Department of Oncology, The Changzhou Wujin People's Hospital, Jiangsu Province, 213017, China \\ ${ }^{2}$ Institute of Life Sciences, Jiangsu University, Zhenjiang, Jiangsu Province, 212013, China \\ "These authors contributed equally to this work \\ Correspondence to: Jianhua Jin, email: jianhuajin88@sina.com \\ Yongzhong Hou, email: houyz@ujs.edu.cn \\ Keywords: HBXIP; PPARS; NF-KB; proliferation; colonic cancer
}

Received: July 10,2017 Accepted: November 14, $2017 \quad$ Published: December 08, 2017

Copyright: Liv et al. This is an open-access article distributed under the terms of the Creative Commons Attribution License 3.0 (CC BY 3.0), which permits unrestricted use, distribution, and reproduction in any medium, provided the original author and source are credited.

\section{ABSTRACT}

Hepatitis B X-interacting protein (HBXIP, also termed as LAMTOR5) plays a crucial role in regulation of cancer progression, while the mechanism is still unclear. Here we found that HBXIP increased the expression of PPARD (peroxisome proliferatoractivated receptor- $\delta$ ) in gene and protein levels of SW480 or HT-29 colonic cancer cells. Chromatin immunoprecipitation and luciferase reporter assays showed that HBXIP occupied the core promoter $(-1079 /-239 \mathrm{nt})$ regions of PPARD and that HBXIP activated the transcription activity of PPARס in an NF-KB (p65)-dependent manner. Moreover, Co-immunoprecipitation and immunofluorescence analysis showed that HBXIP bound to NF-KB/p65 in the cells. Interestingly, we found that PPARס could conversely increase the expression of NF-KB/p65 through activating its transcription activity. In addition, the clinical observations showed that both HBXIP and PPARס were highly expressed in colonic carcinoma, and HBXIP expression was positively associated with that of PPARס in the clinical specimen. Importantly, HBXIP expression levels were positively correlated with the clinical pathological parameters including lymph node metastasis and advanced TNM stage. These findings suggest that HBXIP served as a co-activator to activate the positive feedback regulations of NF-KB/PPARס, which promoted the fast proliferation of the colonic cancer cells. Therapeutically, HBXIP may serve as a potential drug target of colonic cancer cells.

\section{INTRODUCTION}

Colonic cancer is the third death-related cancer in the worldwide, accounting for more than 1,300,000 new cases annually and its incidence has sharply increased over the past two decades [1]. Hepatitis B X-interacting protein (HBXIP), a new oncoprotein also known as LAMTOR5 [2], is a conserved $\sim 18 \mathrm{KDa}$ protein originally identified by its interaction with the hepatitis $\mathrm{B}$ virus $\mathrm{X}$ protein [3]. Previous studies have reported that HBXIP functions as a coactivator of multiple oncogenic transcription factors, such as TF-IID, SP1, STAT3 on the promotion of proliferation and metastasis of breast cancer cells [4-6].
However, the mechanism by which HBXIP enhances the growth of colonic cancer remains poorly documented.

Peroxisome proliferator-activated receptors (PPARs) are a nuclear receptor family of ligand-inducible transcription factors, which have three isoforms: PPAR $\alpha, \delta$ and $\gamma$, which are expressed in all cell types of the brain [7, 8]. Many researchers have investigated the neuroprotective properties of PPAR agonists [9-11]. The efficiency of PPAR $\delta$ agonists in neurodegenerative disease animal models have been reviewed $[12,13]$. To date, studies demonstrate that PPAR $\delta$ also play crucial role in the regulation of cell growth and metabolism of glucose and lipids [14-16]. PPAR $\delta$ is highly expressed in colonic cells and implicated in colonic tumorigenesis, and its 
expression is elevated in human colorectal carcinoma specimen [17]. PPAR $\delta$ also enhances the expression of VEGF, an angiogenic factor, in colonic carcinoma cells [18]. Moreover, the activation of PPAR $\delta$ is associated with oncogenic pathways such as the K-Ras and APC/ $\beta$-catenin/Tcf pathway [19]. PPAR $\delta$ deficiency disrupts hypoxia-mediated tumorigenic potential of colonic cancer cells [20]. Additionally, PPAR $\delta$ is required for chronic colonic inflammation and colitisassociated carcinogenesis [21].

In the present study, we investigated the mechanism by which HBXIP promoted the proliferation of colonic cancer cells. Our data indicate that the oncoprotein HBXIP, functioned as a co-activator of NF- $\mathrm{NB}(\mathrm{p} 65)$ or PPAR $\delta$, transactivated the promoter activity of PPAR $\delta$ or NF$\kappa \mathrm{B}$, and enhanced the expression of PPAR $\delta$ and NF- $\kappa \mathrm{B}$ in mRNA and protein levels in a positive feedback loop manner, leading to the fast growth of colonic cancer cells. These findings contribute new insight into the mechanism by which HBXIP enhances the proliferation of colonic cancer cells, and also provide a potential target for cancer treatment.

\section{RESULTS}

\section{HBXIP up-regulates PPARס expression in colonic cancer cells}

Studies had demonstrated that HBXIP (LAMTOR5) expression was up-regulated in many types of cancers $[4,22,23]$. And PPAR $\delta$ is highly expressed in colonic cells and implicated in colonic tumorigenesis [17]. Then we wondered whether the expression of HBXIP was associated with that of PPAR $\delta$ in the colonic cancer cells. Intriguingly, we observed that the mRNA and protein levels of PPAR $\delta$ were significantly elevated by transiently transfecting HBXIP expression plasmids (pCMV-HBXIP) in colonic cancer SW480 and HT-29 cells (Figure 1A, 1B and Supplementary Figure 1B). Conversely, the expression of PPAR $\delta$ was remarkably reduced when HBXIP was knockdown by transiently transfecting HBXIP siRNA (si-HBXIP) in colonic cancer SW480 or HT-29 cells respectively (Figure 1C and 1D). Therefore, we conclude that the oncoprotein HBXIP can up-regulate the expression of PPAR $\delta$ in colonic cancer cells.

\section{HBXIP promotes PPAR $\delta$ gene transcription activity}

Our previous report indicated that HBXIP could function as a co-activator of TFIID to activate the Lin28B transcription activities [4]. Accordingly, we wondered whether HBXIP could be involved in the transcriptional regulation of PPAR $\delta$. As expected, HBXIP could occupy the PPAR $\delta$ promoter regions by chromatin immunoprecipitation (ChIP) assays (Figure 2A). Then we constructed the PPAR $\delta$ promoter $(-1491 /-239$ nucleotides region) into pGL3-Basic vector and luciferase reporter gene assays were performed, the data showed that the activity of PPAR $\delta$ promoter could be markedly enhanced by HBXIP in SW480 cells (Figure 2B), suggesting that HBXIP up-regulates PPAR $\delta$ expression via activating $\operatorname{PPAR} \delta$ promoter. Next, we further identified the PPAR $\delta$ promoter core region. Various lengths of the PPAR $\delta$ 5'-flanking regions, including -1491/-239 (pGL31253), -1296/-239 (pGL3-1058), -1079/-239 (pGL3841), -835/-239 (pGL3-597), -599/-239 (pGL3-361) and -389/-239 (pGL3-151), were cloned and transiently transfected into SW480 cells to measure promoter activities respectively. The luciferase reporter gene assays were performed and the results indicated that pGL3-841 exhibited the maximum promoter activity among these promoter regions (Figure 2C), indicating that the region of $-1079 /-239 \mathrm{nt}$ is the promoter core region of PPAR $\delta$. Co-transfections of pCMV-HBXIP or si-HBXIP with pGL3-841 or pGL3-Basic control were performed in SW480 and HT-29 cells respectively. The results demonstrated that the promoter activities of pGL3-841 increased by 4- or 6-fold in the HBXIPtransfected SW480 or HT-29 cells respectively (Figure 2D and $2 \mathrm{E}$ ). Meanwhile, the promoter activities of pGL3841 decreased by 2- or 3-fold in $200 \mathrm{nM}$ /well si-HBXIPtransfected SW480 or HT-29 cells (Figure 2D and 2E). Thus, These results suggest that HBXIP up-regulted the gene expression of PPAR $\delta$ through binding and activating the core promoter $(-1079 /-239 \mathrm{nt})$ of PPAR $\delta$.

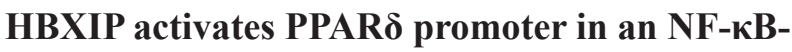 dependent manner}

We next explored the $-1079 /-239$ nt promoter regions for a possible transcription factor binding sites by using GPMiner (http://gpminer.mbc.nctu.edu.tw/). The promoter region $-1079 /-239$ contains various different promoter elements, such as Hsf1 and NF- $\mathrm{BB} / \mathrm{p} 65$. It has been reported that $\mathrm{NF}-\kappa \mathrm{B} / \mathrm{p} 65$ signaling was involved in carcinogenesis [24]. Thus, we hypothesized that HBXIP might activate the PPAR $\delta$ promoter via NF- $\mathrm{BB} / \mathrm{p} 65$. Interestingly, luciferase reporter gene assays indicated that PPAR $\delta$ promoter activity was remarkably increased in a dose-dependent manner in SW480 cells treated with p65 expression plasmid (pCMV-p65) (Figure 3A), suggesting that NF- $\kappa \mathrm{B}$ can activate the transcription activity of PPAR $\delta$. To further validate whether NF- $\kappa B$ is an important transcription factor of $\operatorname{PPAR} \delta$ promoter, we reconstructed the pGL3-841 mutant, which deleted the NF- $\kappa \mathrm{B}$ binding sequence (PPAR $\delta$ promoter mutant), and performed the luciferase reporter gene assays. Data showed that the activity of pGL3-841 mutant sharply decreased compared to that of the normal promoter. Moreover, HBXIP failed to activate the pGL3-841 mutant (Figure 3B), indicating that HBXIP activates the PPAR $\delta$ promoter activity in an NF- $\kappa \mathrm{B}$-dependent manner. To further verify that HBXIP activates PPAR $\delta$ transcription activity via $\mathrm{NF}-\kappa \mathrm{B}$, the quantitative real-time PCR was performed and the results showed that the mRNA levels 
of PPAR $\delta$ of SW480 cells co-transfected with pCMV-p65/ pCMV-HBXIP markedly increased compare to that of the cells transfected with pCMV-p65. The mRNA levels of PPAR $\delta$ of cells co-transfected with pCMV-p65/ si-HBXIP decreased compared to that of cells transfected with pCMV-p65 (Figure 3C and Supplementary Figure 2A), indicating that HBXIP up-regulates PPAR $\delta$ expression via NF- $\kappa$ B. Moreover, the mRNA levels of PPAR $\delta$ of SW480 cells transfected with si-p65 decreased relative to that of cells transfected with si-Control, and HBXIP failed to enhance the PPAR $\delta$ mRNA levels in the cells treated with transfecting si-p65 (Figure 3D), indicating that HBXIP up-regulated PPAR $\delta$ expression in a NF- $\kappa$ Bdependent manner. We then detected the protein levels of PPAR $\delta$ by Western blotting. The results demonstrated that over-expression of HBXIP increased PPAR $\delta$ expressions in SW480 or HT-29 cells. However, the knockdown of p65 abolished the increase of PPAR $\delta$ proteins-induced by HBXIP (Figure 3E, 3F and Supplementary Figure 2B), indicating that HBXIP boosts the expression of PPAR $\delta$ in a NF- $\kappa \mathrm{B}-$ dependent manner in cancer cells.

To further elucidate the relationship between HBXIP and NF- $\kappa \mathrm{B}$, co-immunoprecipitation (Co-IP) assays were performed and the results displayed that HBXIP and NF$\kappa \mathrm{B}$ could bind to each other in HT-29 cells (Figure 4A). Moreover, immunofluorescence (IF) images showed that the proteins of HBXIP and p65 were mainly located in the cytoplasm and a small amount of HBXIP and p65 proteins co-localized in the nucleus (Figure 4B), the similar results were also confirmed by confocal laser scanning microscope (Figure 4C and Supplementary Figure 3), showing that HBXIP and NF- $\kappa$ B could bind to each other in the nucleus in the cells. Moreover, the western blot results showed that over-expression of
A

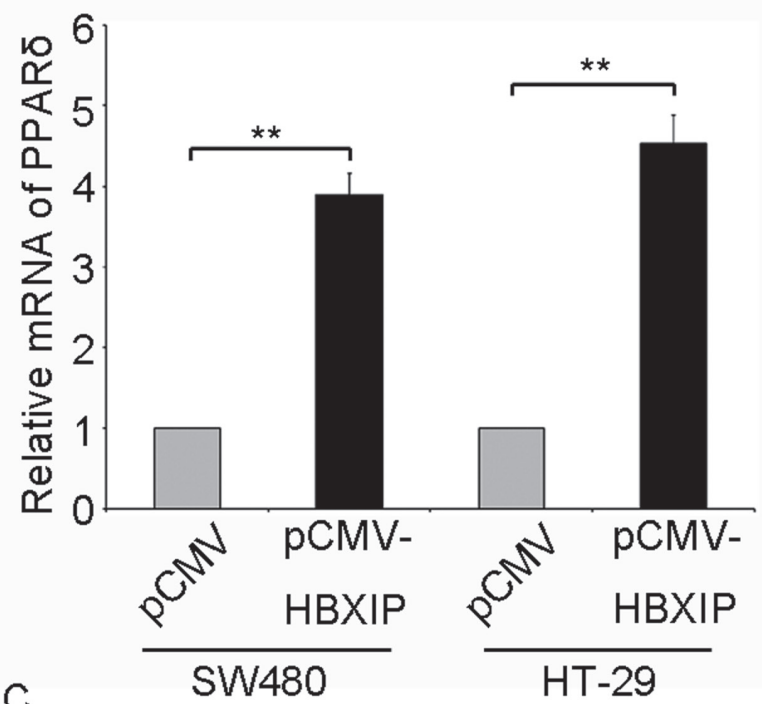

C

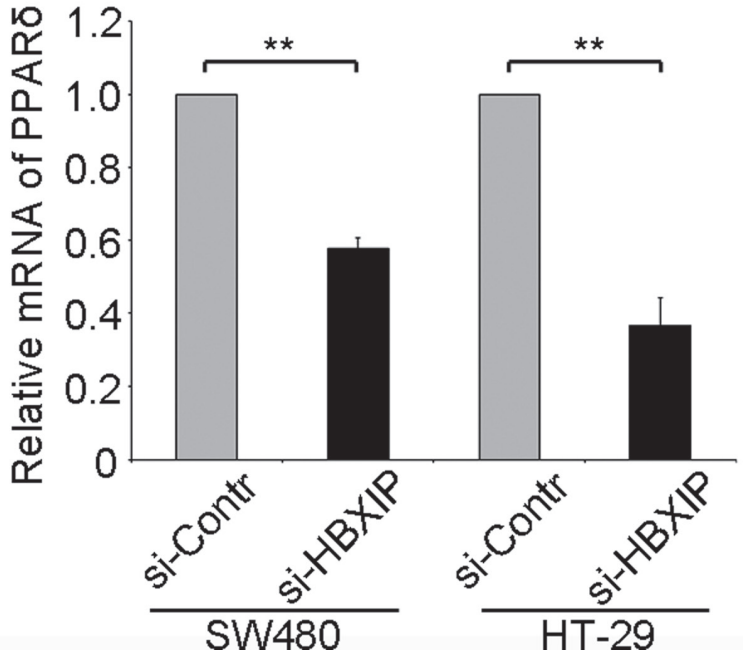

B
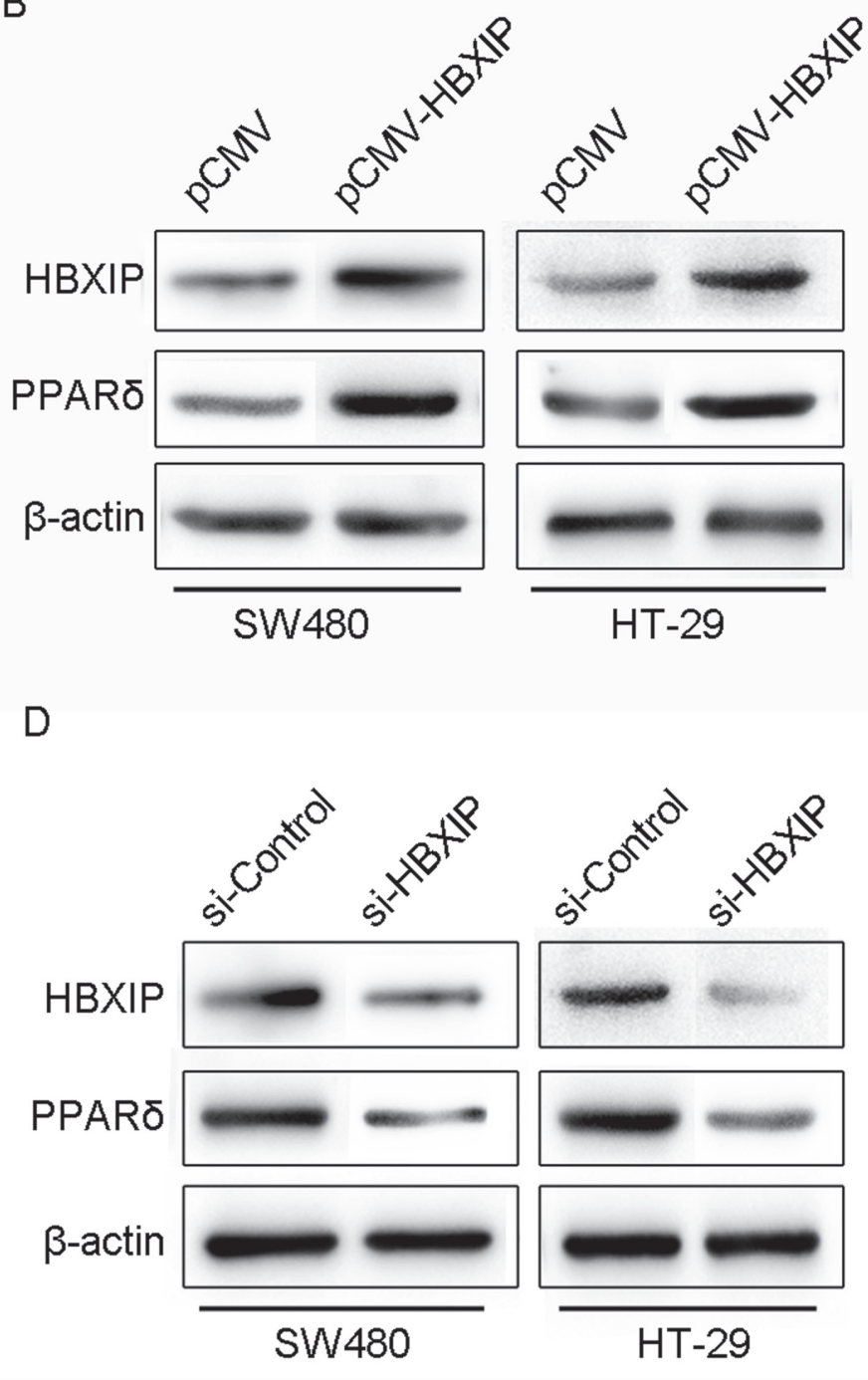

Figure 1: HBXIP up-regulates PPAR $\delta$ expression in colonic cancer cells. (A) The mRNA or protein (B) levels of PPAR $\delta$ were tested by qRT-PCR or Western blot analysis in SW480 and HT-29 cells transiently transfected with pCMV (1 $\mu \mathrm{g})$ or pCMV-HBXIP $(1 \mu \mathrm{g})$, respectively. The mRNA $(\mathbf{C})$ and protein (D) levels of PPAR $\delta$ were detected by qRT-PCR or Western blot in SW480 or HT-29 cells transiently transfected with negative control siRNA (si-Control, $100 \mathrm{nM}$ ) or HBXIP siRNA (si-HBXIP, 100 nM), respectively. 
A
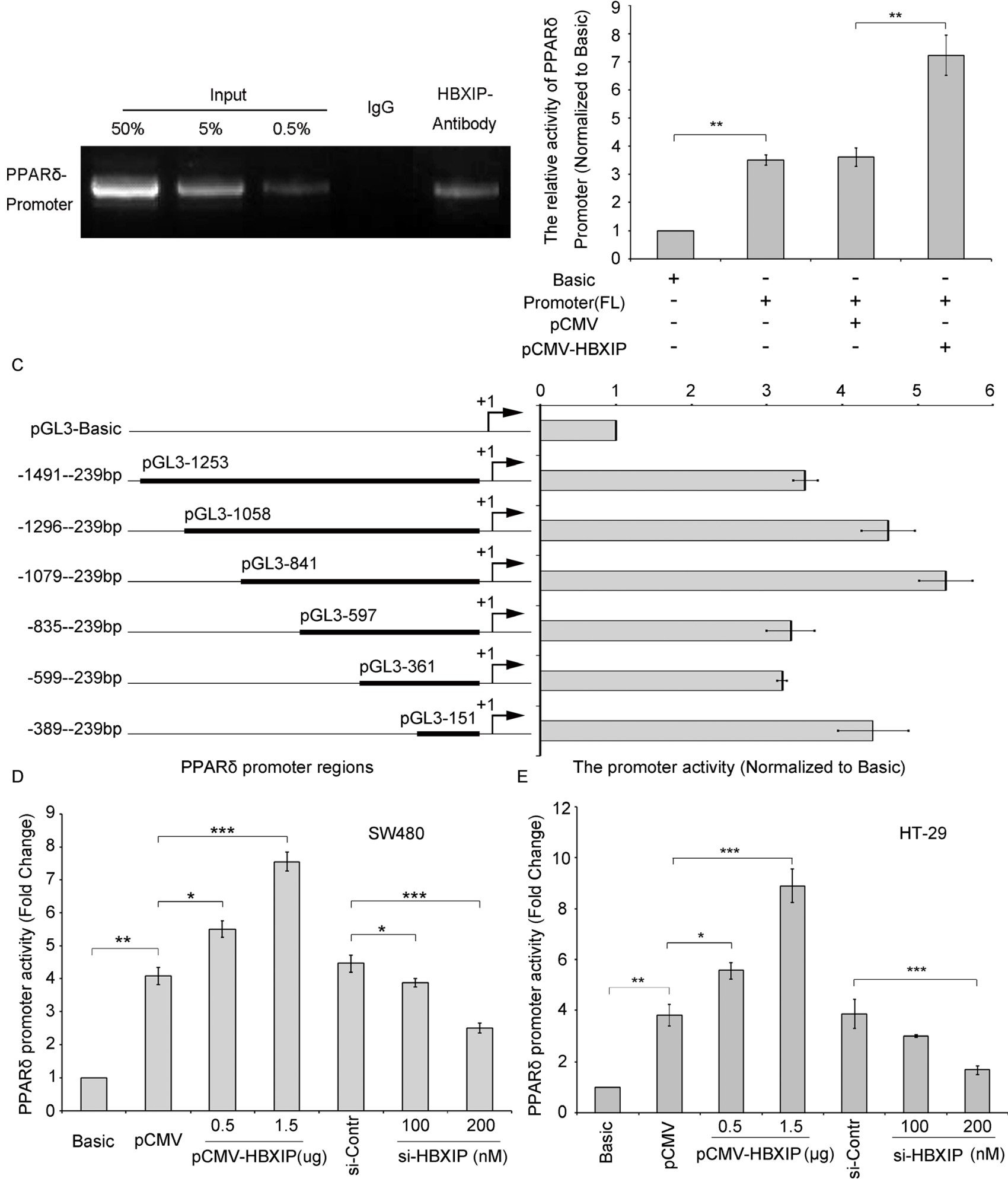

B

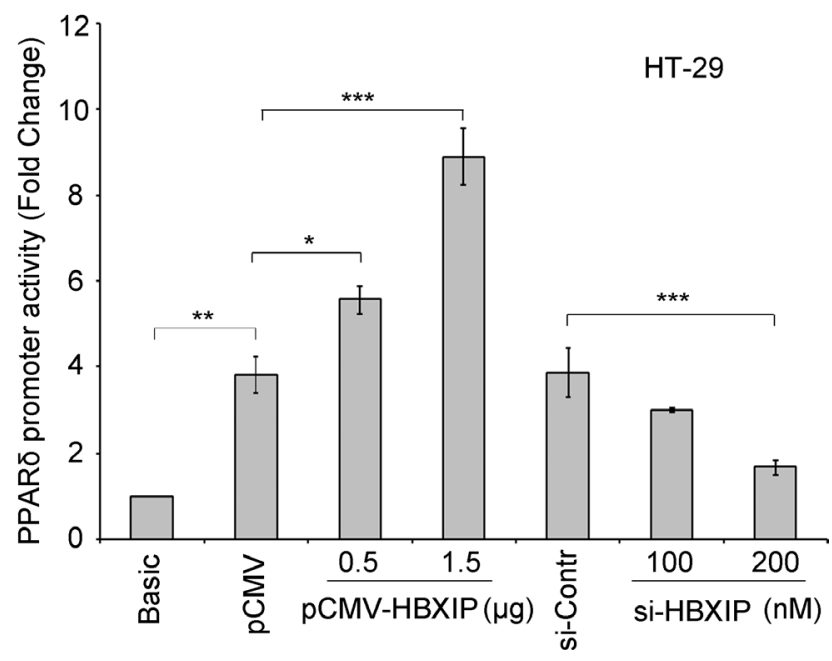

Figure 2: HBXIP is able to activate PPAR $\delta$ transcription activity. (A) The interaction between HBXIP and PPAR $\delta$ promoter was detected by ChIP assay. The ChIP products were validated by sequencing and the data presented are from three independent experiments. (B) The promoter activity of PPAR $\delta$ was tested by dual luciferase reporter system in SW 480 cells transiently transfected with pCMV $(0.5 \mu \mathrm{g})$ or pCMV-HBXIP $(0.5 \mu \mathrm{g})$. (C) The relative activities of different promoter regions of PPAR $\delta$ were examined by dual luciferase reporter system respectively. (D and E) The relative activities of the core promoter (-1079/-239 nt) of PPAR $\delta$ were measured by dual luciferase reporter system in SW480 or HT-29 cells transiently transfected with pCMV-HBXIP (0.5 and $1.5 \mu \mathrm{g})$ or si-HBXIP (100 or $200 \mathrm{nM})$, respectively. ${ }^{*} p<0.05,{ }^{* *} p<0.01,{ }^{* * *} p<0.001$. Student's $t$-test. All experiments were performed three times. 
A

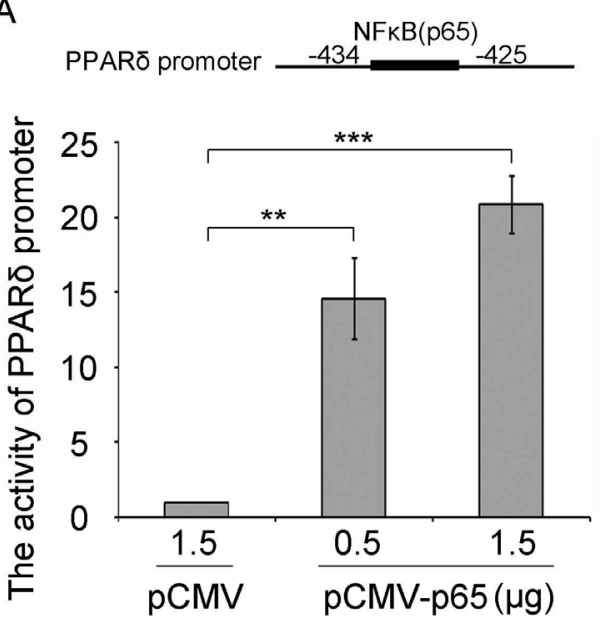

C

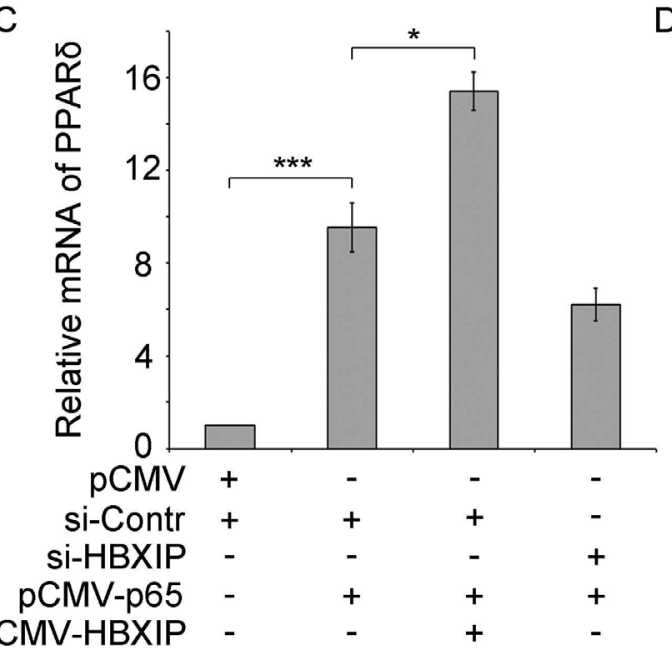

$E$

SW480

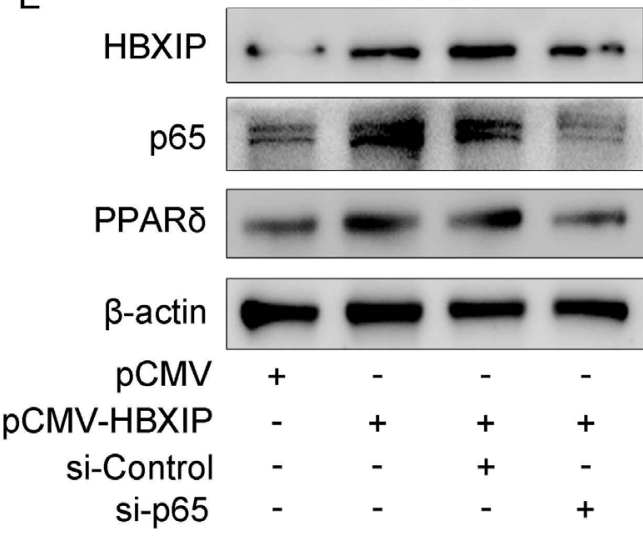

B

$\mathrm{D}$
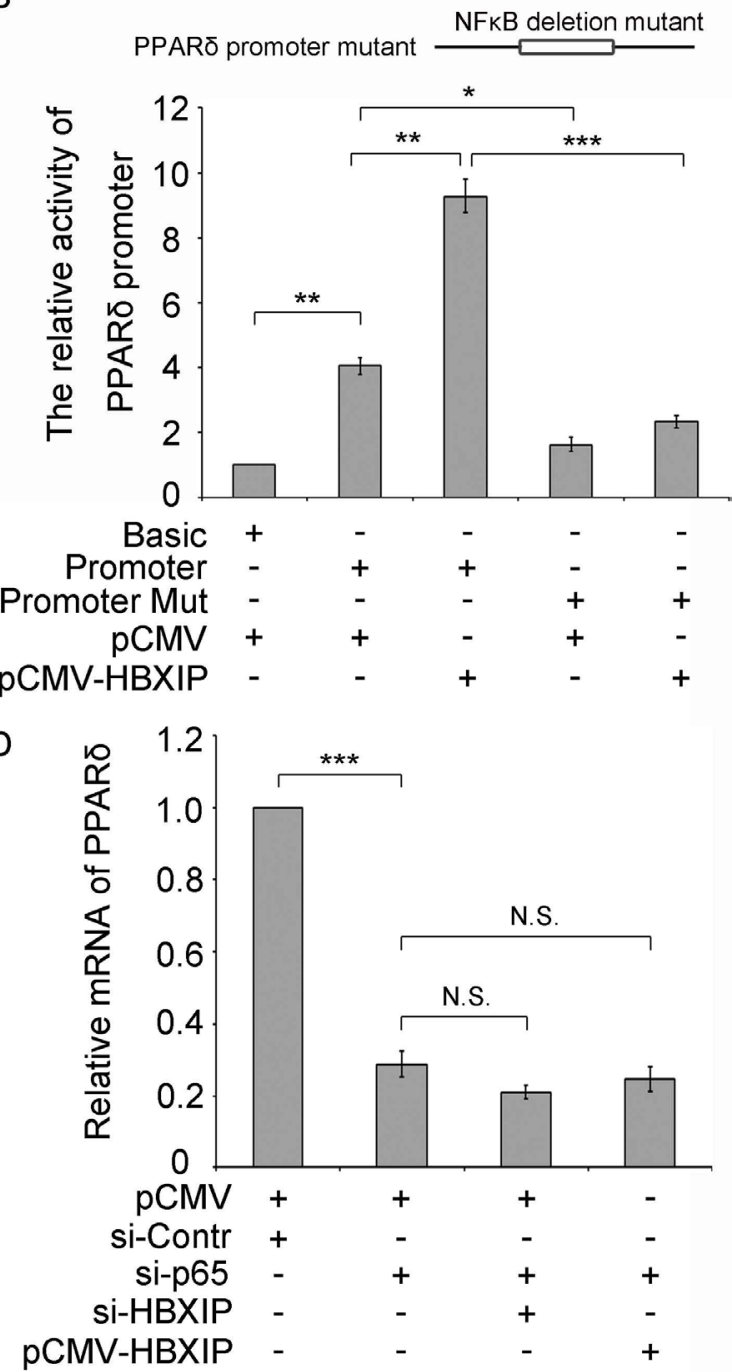

$\mathrm{F}$

HT-29

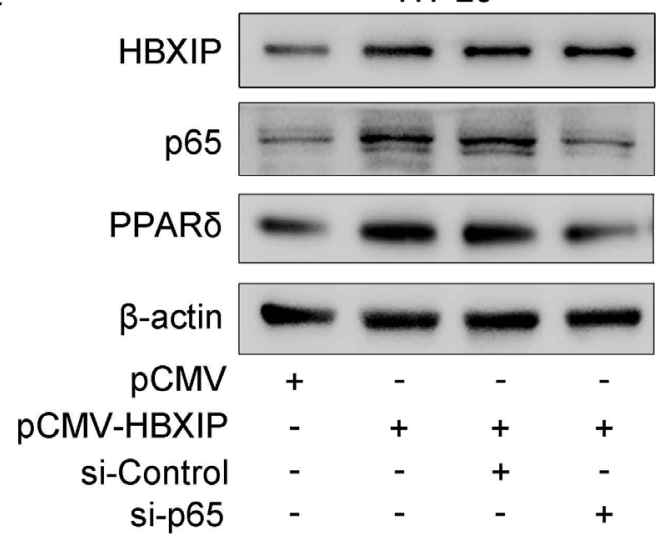

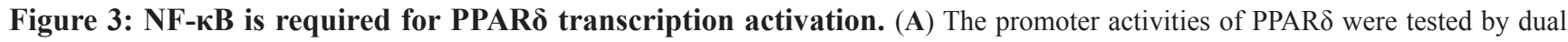
luciferase reporter system in SW480 cells transiently transfected with pCMV (1.5 $\mu \mathrm{g})$ or pCMV-p65 (0.5 or $1.5 \mu \mathrm{g})$, respectively. (B) The relative activities of PPAR $\delta$ promoter and promoter mutant (NF- $\mathrm{KB}$ binding sequence deletion mutant) were detected by dual luciferase reporter system in SW480 cells transiently transfected with pCMV $(1 \mu \mathrm{g})$ or pCMV-HBXIP $(1 \mu \mathrm{g})$. (C and D) The mRNA levels of PPAR $\delta$ were detected by qRT-PCR in SW480 cells transiently cotransfected with pCMV/si-Control, si-Control/pCMV-p65, si-HBXIP/pCMV-p65 si-Control/pCMV-HBXIP/pCMV-HBXIP, pCMV/si-p65, pCMV/si-p65/si-HBXIP and si-p65/pCMV-HBXIP, respectively. (E and F) The expression levels of p65 and PPAR $\delta$ were tested by Western blot in SW480 or HT-29 cells transiently transfected with pCMV $(1 \mu \mathrm{g})$, pCMV-HBXIP $(1 \mu \mathrm{g})$, pCMV-HBXIP (1 $\mu \mathrm{g}) /$ si-Control (100 nM) and pCMV-HBXIP $(1 \mu \mathrm{g}) / \mathrm{si}$-p65 (100 nM), respectively. 
HBXIP could elevate the expression of NF- $\mathrm{B} / \mathrm{p} 65$ both in the nucleus and cytoplasm (Supplementary Figure 2E). Taken together, we conclude that HBXIP, as a c o-activator of NF- $\kappa \mathrm{B}$, promotes the transcription activity of PPAR $\delta$, and enhances its expression in mRNA and protein levels.

\section{PPAR $\delta$ regulates the expression of NF- $\mathrm{NB}$ in colonic cancer cells}

Next, we wondered whether PPAR $\delta$ could enhance the expression of NF- $\kappa \mathrm{B}$ in colonic cancer cells. Interestingly, we observed that $\operatorname{PPAR} \delta$ expression could positively regulate the expression of NF- $\kappa \mathrm{B}$ in the cells. Western blot assays were performed in SW480 and HT29 colonic cancer cells and HEK293T cells. The results indicated that the expression of $\mathrm{NF}-\kappa \mathrm{B}$ was decreased in SW480 and HT-29 cells transfected with PPAR $\delta$ siRNA (si-PPAR $\delta$ ) (Figure 5A). The similar results were also confirmed in the HEK293T cells (Supplementary Figure 2D), suggesting that PPAR $\delta$ could up-regulate the expression of $\mathrm{NF}-\kappa \mathrm{B}$ in the colonic cancer cells. Then, quantitative real-time PCR (qRT-PCR) were performed and the data showed that the mRNA levels of NF- $\kappa \mathrm{B}$ could be remarkably decreased in the cells
A

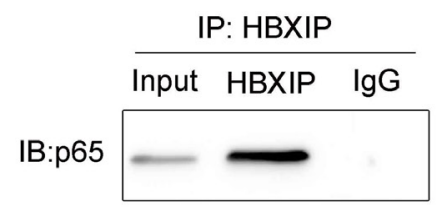

B

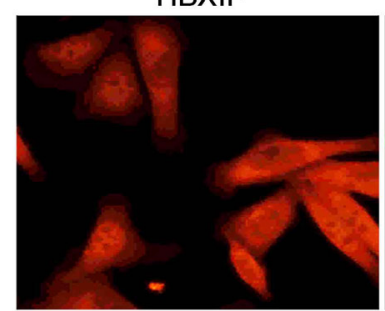

DAPI

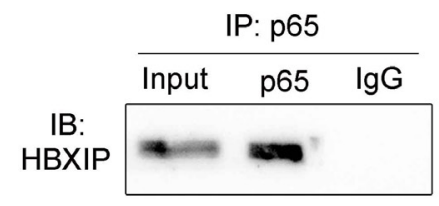

C
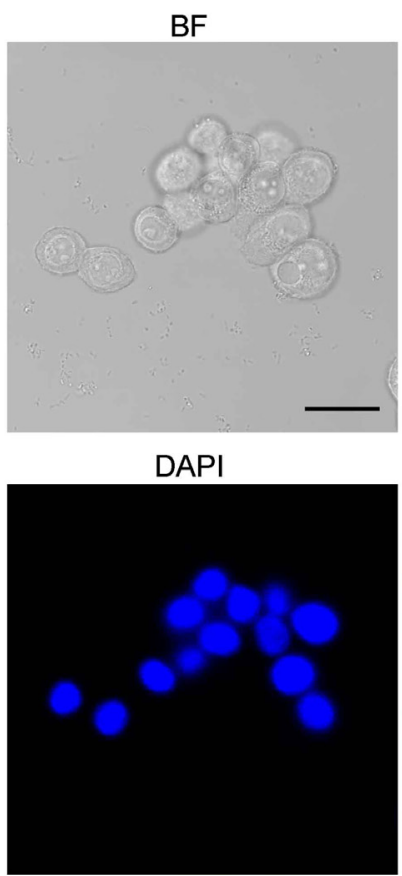

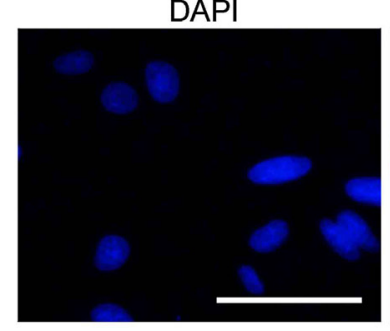

$\mathrm{NF}-\mathrm{kB}(\mathrm{p} 65)$

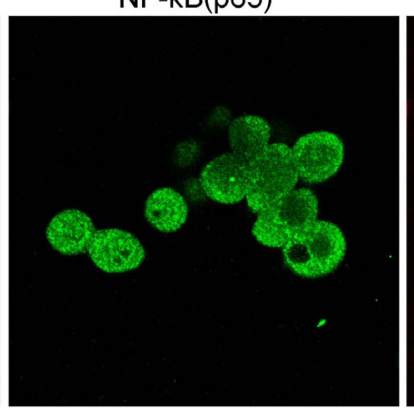

HBXIP/p65

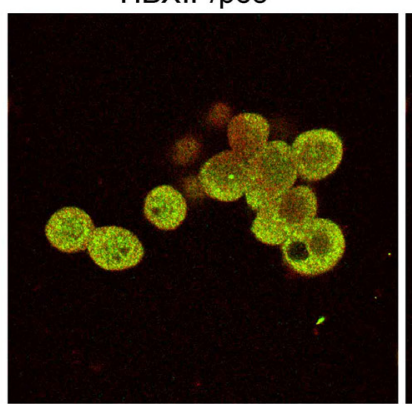

$\mathrm{NF}-\mathrm{kB}(\mathrm{p} 65)$

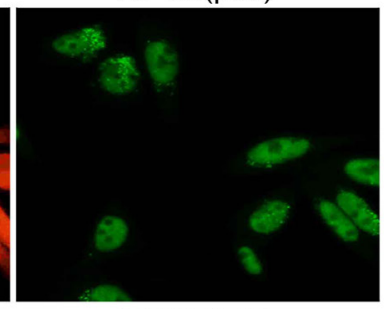

HBXIP/p65
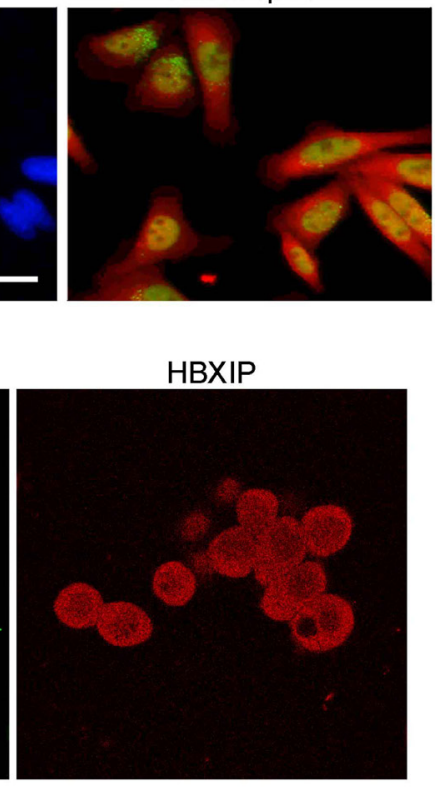

HBXIP/p65/DAPI

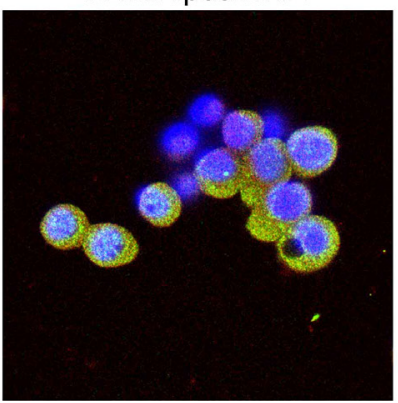

Figure 4: HBXIP binds to NF-kB(p65) in cancer cells. (A) The interaction between HBXIP and NF- $\kappa B$ was detected by Coimmunoprecipitation (Co-IP) in the HT-29 cancer cells. (B) Immunofluorescence and confocal laser scanning microscope (C) were performed to detect the association between HBXIP and NF- $\kappa$ B in the HT-29 cells transfected with pCMV-HBXIP (1 $\mu \mathrm{g})$. The scale bar of immunofluorescence and confocal laser scanning miscroscope is $100 \mu \mathrm{m}$ and $25 \mu \mathrm{m}$, respectively. 
transfected with si-PPAR $\delta$ (Figure 5B and Supplementary Figure 2C), suggesting that $\operatorname{PPAR} \delta$ up-regulated the transcription activity of NF- $\kappa \mathrm{B}$. We detected the promoter activity of NF- $\mathrm{BB}$ by luciferase reporter gene assays, data showed that the promoter activity of NF- $\kappa B$ could be decreased in the cells treated with si-PPAR $\delta$ (Figure 5C and Supplementary Figure 4C), suggesting that PPAR $\delta$ could activate the transcription activity of NF- $\kappa$ B. Taken together, we conclude that $\operatorname{PPAR} \delta$ up-regulated the expression of NF- $\kappa \mathrm{B}$ via activating its transcription activity in colonic cancer cells.

\section{PPAR $\delta$ is required for HBXIP-induced proliferation of colonic cancer cells}

Based on the hypothesis that PPAR $\delta$ is involved in the HBXIP-induced cell proliferation, we performed Methylthiazolyldiphenyl-tetrazolium bromide (MTT) assays in SW480 or HT-29 cells by transfecting with pCMV $(0.5 \mu \mathrm{g}), \mathrm{pCMV}-\mathrm{HBXIP}(0.5 \mu \mathrm{g})$, pCMV-HBXIP $(0.5 \mu \mathrm{g}) / \mathrm{si}-\mathrm{Control}(100 \mathrm{nM})$ or pCMV-HBXIP $(0.5 \mu \mathrm{g}) /$ si-PPAR $\delta(100 \mathrm{nM})$ respectively. Consistent with the hypothesis, the data clearly indicated that the proliferation

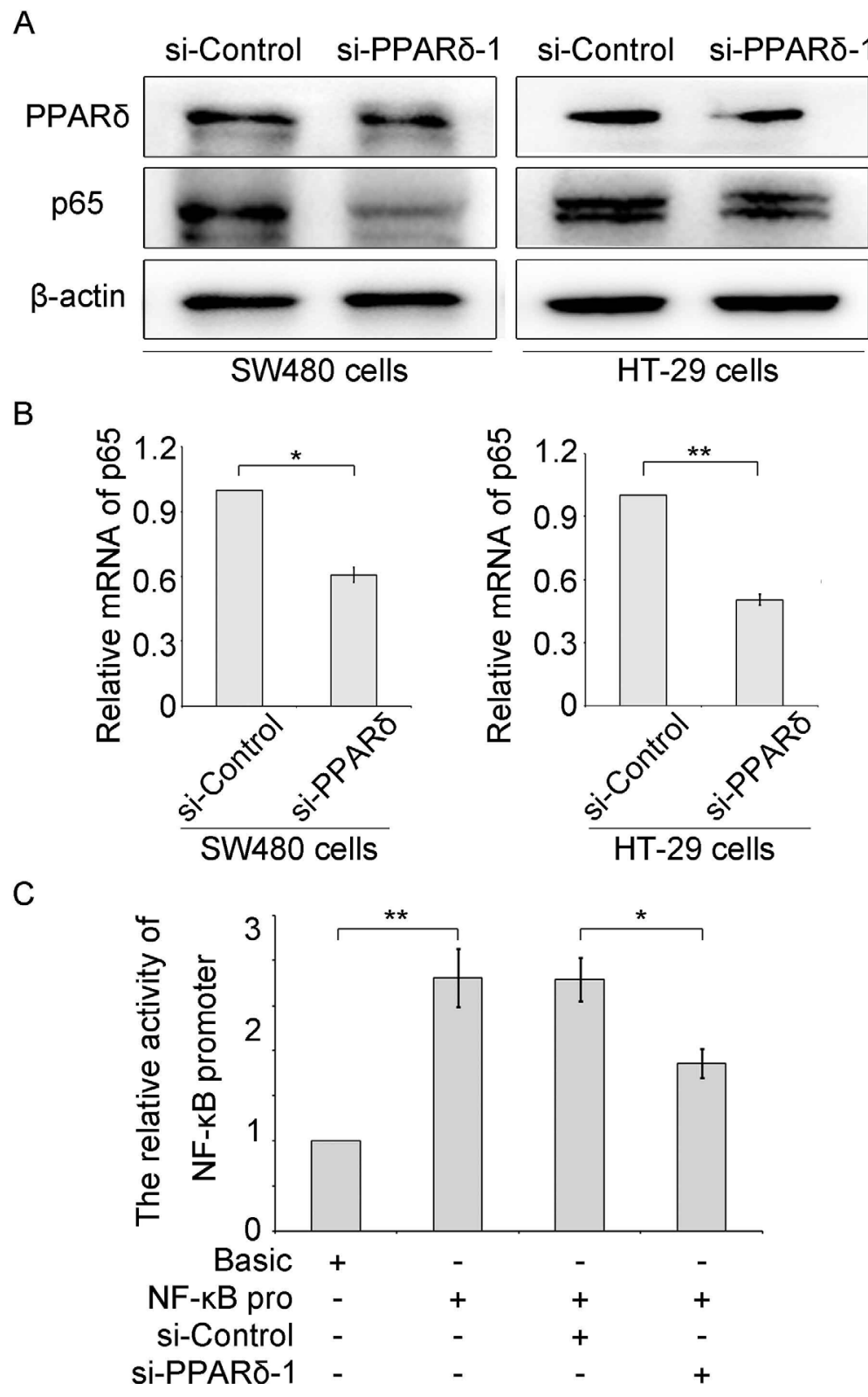

Figure 5: PPAR $\delta$ enhances the expression of NF- $\kappa B$ via activating its transcription activity. (A) The protein levels of $N F-\kappa B$ (p65) were detected in SW480 and HT-29 colonic cancer cells transfected with si-PPAR $\delta$ or si-Control (100 nM), respectively. (B) The mRNA levels of NF- $\kappa B$ were measured by quantitative real-time PCR in the cells treated with si-PPAR $\delta$ or si-Control (100 nM). (C) The promoter activity of NF- $\mathrm{KB}$ was tested by luciferase reporter gene assays in the colonic cancer HT-29 cells transfected with pGL3-Basic $(1 \mu \mathrm{g})$, pGL3-NF-kB promoter $(1 \mu \mathrm{g})$, si-Control $(100 \mathrm{nM})$ and si-PPAR $\delta(100 \mathrm{nM})$, respectively. 
ability of SW480 was increased by HBXIP overexpression. However, the knockdown of PPAR $\delta$ abolished the HBXIP-induced proliferation (Figure 6A, 6B and Supplementary Figure 4A), the similar results were also confirmed by colony formation assays (Supplementary Figure 4B), suggesting that HBXIP promoted the proliferation of colonic cancer cells through activating PPAR $\delta$. Moreover, ethynyldeoxyuridine (EdU) assays were performed and the data showed the similar results of MTT assays, that is HBXIP expression enhanced the proliferation of SW480 or HT-29 cells, and the increase was abolished by the addition of si-PPAR $\delta(100 \mathrm{nM})$ (Figure 6C, 6D and Supplementary Figure 4D). Taken together, these data strongly suggest that HBXIP promoted the proliferation of colonic cancer cells via activating PPAR $\delta$.

\section{Association between HBXIP and clinicopathological characteristics}

We have found that HBXIP could promote the proliferation of colonic cancer cells. Then we wondered whether the expression levels of HBXIP were associated with specific clinicopathological parameters in colonic cancer patients. 148 patients (Supplementary Table 1) were separated equally into two groups according to the expression levels of HBXIP measured by quantitative realtime PCR (qRT-PCR). We found that HBXIP expression levels were strongly correlated with the clinical stage including lymph node metastasis and advanced TNM stage (Table 1). However, there were no statistically significant associations between HBXIP expression and other clinicopathological data, including Age, Gender,
A

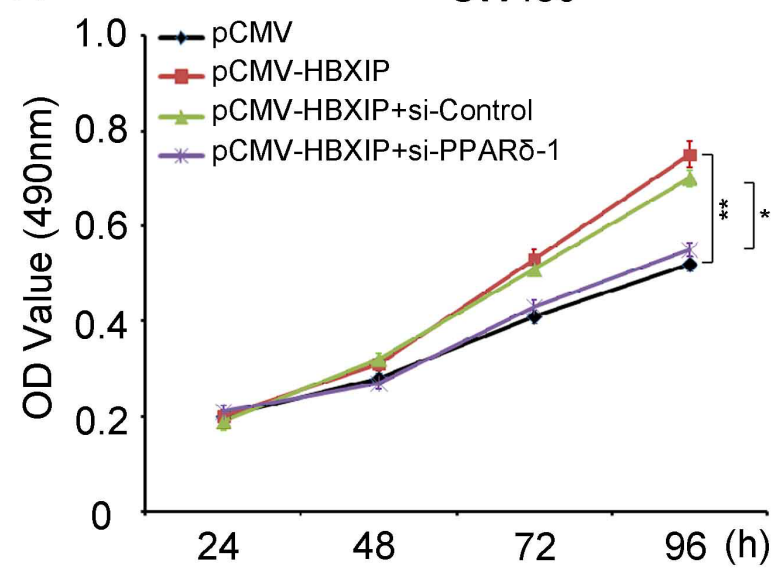

C

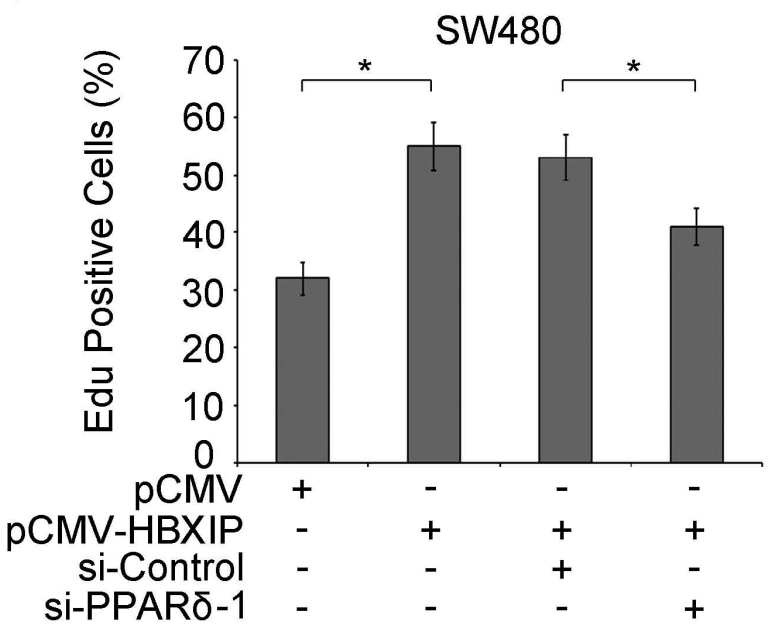

B

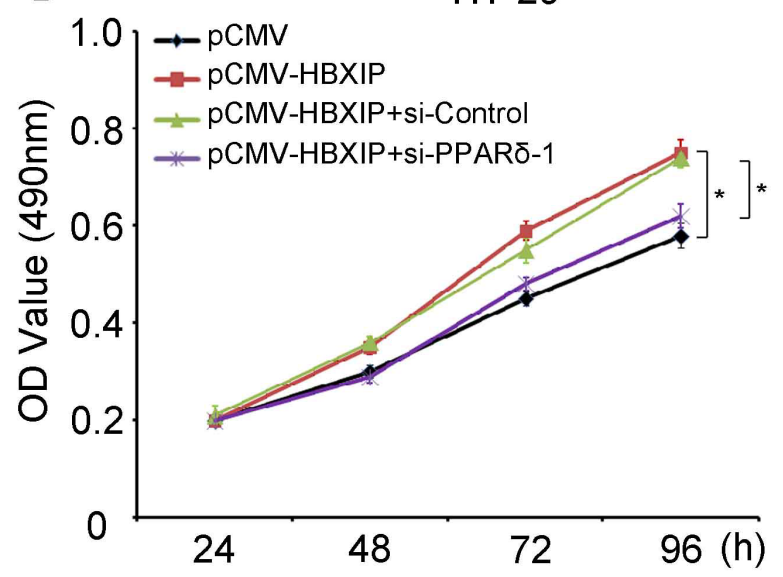

D

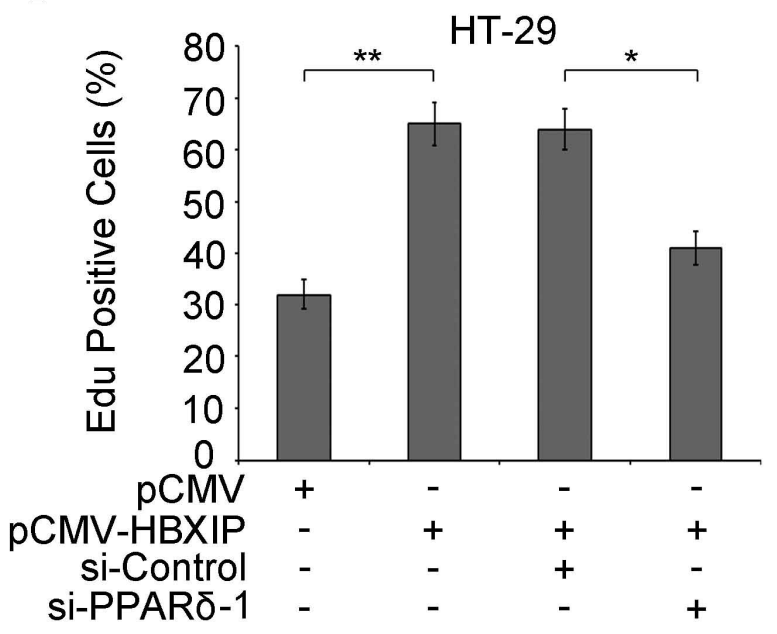

Figure 6: PPAR $\delta$ is required for HBXIP-induced proliferation of colonic cancer cells. (A) The effect of PPAR $\delta$ knowdown on the proliferation of SW480 or HT-29 (B) cells transiently cotransfected with pCMV (1 $\mu \mathrm{g})$, pCMV-HBXIP $(1 \mu \mathrm{g})$, pCMV-HBXIP $(1 \mu \mathrm{g}) / \mathrm{si}$-Control $(100 \mathrm{nM})$ and pCMV-HBXIP $(1 \mu \mathrm{g}) / \mathrm{si}-\mathrm{PPAR} \delta(100 \mathrm{nM})$ were measured by MTT assays $(\mathbf{C})$ or detected by EdU assays $(\mathbf{D})$, respectively. 
Table 1: The relationship between HBXIP expression and clinicopathologic parameters in Colon cancer patients

\begin{tabular}{|c|c|c|c|}
\hline \multirow{2}{*}{ Clinicopathologic parameters } & \multicolumn{2}{|c|}{ HBXIP expression ${ }^{1}$} & \multirow{2}{*}{$P$-value } \\
\hline & High $(\%)$ & Low (\%) & \\
\hline All cases & 74 & 74 & \\
\hline Age (years) & & & 0.735 \\
\hline$\leq 65$ & $27(36.5)$ & $29(39.2)$ & \\
\hline$>65$ & $47(63.5)$ & $45(60.8)$ & \\
\hline Gender & & & 0.139 \\
\hline Male & $41(55.4)$ & $32(43.2)$ & \\
\hline Female & $33(44.6)$ & $42(56.8)$ & \\
\hline Tumor Size (cm) & & & 0.079 \\
\hline$\leq 5$ & $55(74.3)$ & $45(60.8)$ & \\
\hline$>5$ & $19(25.7)$ & $29(39.2)$ & \\
\hline Differentiation & & & 0.603 \\
\hline low & $35(47.3)$ & $29(39.2)$ & \\
\hline moderate & $37(50)$ & $43(58.1)$ & \\
\hline High & $2(2.7)$ & $2(2.7)$ & \\
\hline Lymph node metastasis & & & $0.003^{* *}$ \\
\hline N0M0 & $34(45.9)$ & $52(70.3)$ & \\
\hline N1MO & $25(33.8)$ & $8(10.8)$ & \\
\hline N2M0 & $9(12.2)$ & $11(14.9)$ & \\
\hline M1 & $6(8.1)$ & $3(4.0)$ & \\
\hline TNM Stage & & & $0.003^{* *}$ \\
\hline I, II & $34(45.9)$ & $52(70.3)$ & \\
\hline III, IV & $40(54.1)$ & $22(29.7)$ & \\
\hline
\end{tabular}

${ }^{*} P<0.05,{ }^{* *} P<0.01,{ }^{* * *} P<0.001$, Chi-squared test $P$-value.

${ }^{1}$ Median relative expression level was used as a cutoff to divide the 148 patients into high HBXIP group $(n=74)$ and low HBXIP group $(n=74)$.

Tumor size and Differentiation. The clinicopathological parameters showed that HBXIP expression was positively associated with the development and progression of colonic carcinoma, which suggests that HBXIP may play important roles in the colonic carcinoma and function as a potential factor for predicting tumor malignancy.

\section{HBXIP has a positive correlation with PPAR $\delta$ in clinical colonic carcimoma tissues}

Literatures reported that PPAR $\delta$, a ligand-inducible transcription factor, is highly expressed in colonic cells and involved in colonic tumorigenesis. Thus, we wondered whether the expression of HBXIP was associated with that of PPAR $\delta$ in the clinical colonic cancer patients. We then tested the expression levels of HBXIP (Figure 7A) and PPAR $\delta$ (Figure 7B) of 83 cases of colonic paraffinembedded specimen and 12 cases of normal colonic tissues by immunohistochemical assays (Supplementary Table 3), the results demonstrated that Both HBXIP and PPAR $\delta$ were highly expressed in the colonic tumor tissues and showed a positive correlation between HBXIP and PPAR $\delta$ expression in the carcinoma tissues, which suggests that HBXIP had played important roles in the progression of colonic carcinoma cells. Moreover, quantitative realtime PCR were performed to test the expression levels of HBXIP and PPAR $\delta$ of the colonic carcinoma tissues from 148 colonic carcinoma paraffin-embedded specimen. The data demonstrated that the expression levels of PPAR $\delta$ had a significant positive correlation with those of HBXIP in colonic carcinoma tissues $(p<0.001$ Wilcoxon signedrank, Figure 7C). Taken together, we conclude that the expression levels of HBXIP are positively associated with those of PPAR $\delta$ in colonic carcinoma tissues, and the HBXIP/ PPAR $\delta$ signaling may have important roles in the colonic tumorigenesis.

\section{DISCUSSION}

HBXIP (LAMTOR5) plays an important role in the promotion of proliferation of breast cancer cells [4-6]. Research reported that HBXIP showed a high 
expression in the colonic cancer cells (https://www. proteinatlas.org/ENSG00000134248-LAMTOR5/tissue) and we also found the different expression levels of HBXIP in the colonic cancer cells by RT-PCR assays (Supplementary Figure 1A). Previous report indicated that HBXIP functioned in the cytoplasm [25], which is consistent with our immunofluorescent results indicated that HBXIP mainly localized in the cytoplasm, while a small amount of HBXIP proteins located in the nuclues (Figure 4H), suggesting HBXIP may have some functions in the nucleus, which is consistent with our previous studies [4, 6]. However, the mechanism by which HBXIP enhances the proliferation of colonic cancer cells is still unclear. Many studies demonstrated that PPAR $\delta$, a
A

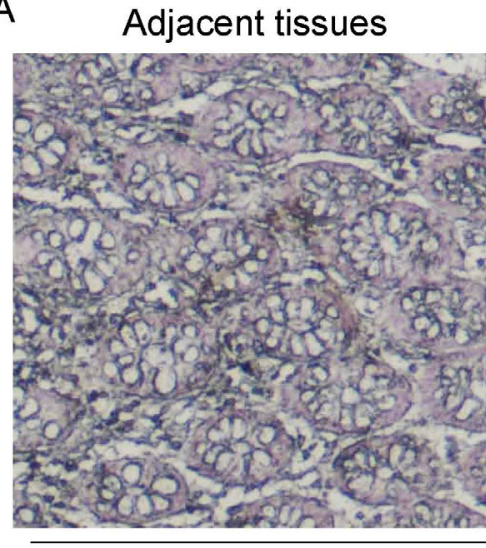

HBXIP Stainning

B

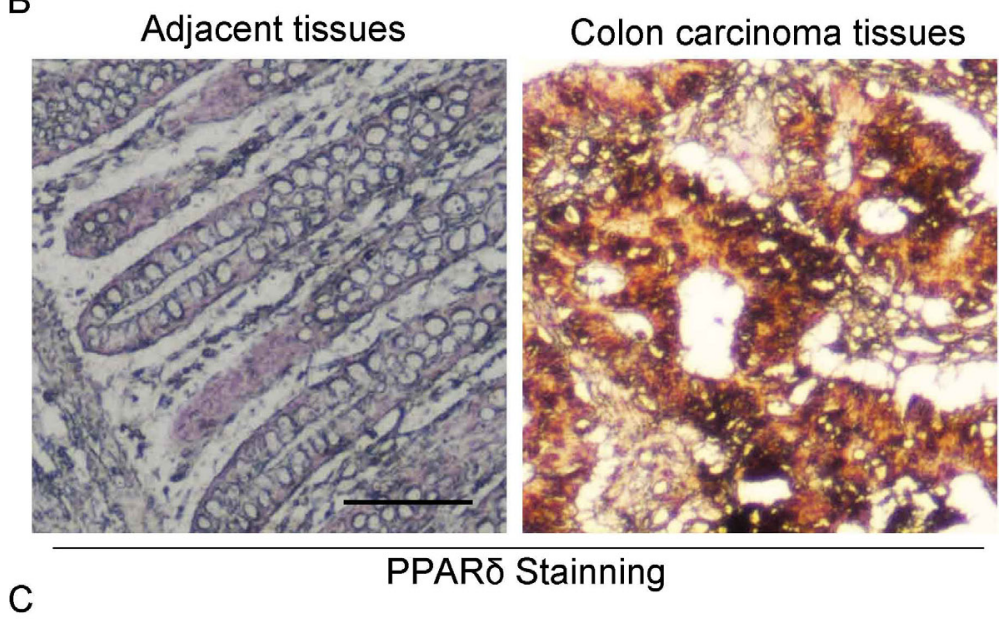

\section{Colon carcinoma tissues}

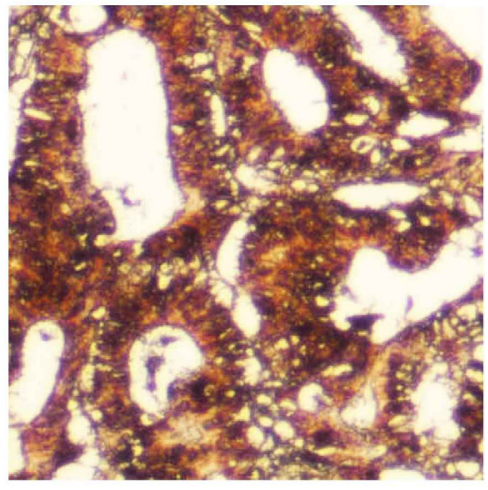

$\mathrm{C}$

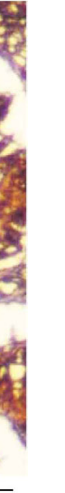 \\ .}

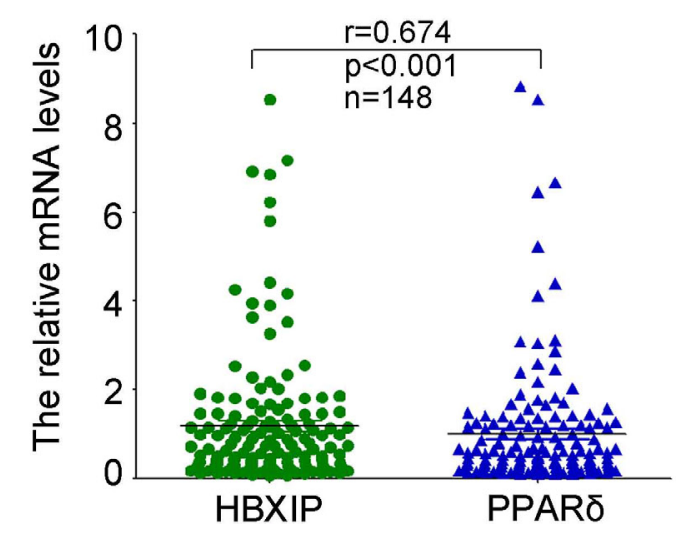

Figure 7: HBXIP has a significant positive correlation with PPAR $\delta$ in clinical colonic carcinoma tissues. (A) The expression levels of HBXIP and PPAR $\delta(\mathbf{B})$ were detected in the colonic carcinoma tissues and adjacent normal tissues by immunohistochemical staining. The scale bar is $100 \mu \mathrm{m}$. (C) The correlation of mRNA levels of HBXIP and PPAR $\delta$ was examined by quantitative real-time PCR (qRT-PCR) in 148 colonic carcinoma paraffin-embedded specimen ( $p<0.001, r=0.674$, Pearson's correlation). 
ligand-inducible transcription factor, plays a critical role in regulating cancer progression, and $\operatorname{PPAR} \delta$-related tumorigenesis was first identified in colorectal cancer [26]. PPAR $\delta$ is also highly expressed in colonic epithelial cells and closely linked to colonic carcinogenesis [20]. Thus, we are interested in whether PPAR $\delta$ is involved in HBXIP-enhanced proliferation of colonic cancer cells. In our study, we investigate how HBXIP functions with $\operatorname{PPAR} \delta$ in promotion of colonic cancer cells.

Many studies indicated that HBXIP promotes the proliferation of breast cancer cells by different signal pathways [27, 28], and HBXIP expression occurs in nearly all tissues [3]. PPAR $\delta$ is also found high expression in colonic epithelial cells and involved in colonic carcinogenesis. Thus, we first tested whether HBXIP is associated with PPAR $\delta$ in colonic cancer cells, we found that HBXIP could up-regulate the expression of PPAR $\delta$ in mRNA and protein levels in SW480 and HT-29 colonic cancer cells, respectively. In order to explore the underlying mechanism by which HBXIP regulates PPAR $\delta$ expression, and according to our previous research results that is HBXIP functioned as a co-activator of transcription factors to activate the transcription activity of target genes [4, 6, 27]. ChIP assay results indicated that HBXIP could occupy on the PPAR $\delta$ promoter, and luciferase report gene data showed that HBXIP could activate the transcription activity of $\operatorname{PPAR} \delta$. We next reconstructed various length of PPAR $\delta$ promoter regions and performed the luciferase reporter gene assays, we found the core region of PPAR $\delta$ promoter, which showed the maximum activity among these different PPAR $\delta$ promoter regions. Our previous study demonstrated that HBXIP could not bind to DNA sequence directly [4]. Next, we predicted the possible transcription factors of PPAR $\delta$ promoter using the GPMiner (http://gpminer.mbc. nctu.edu.tw/). NF- $\kappa \mathrm{B}$ transcription factor was screened out and previous literature reported that $\mathrm{NF}-\kappa \mathrm{B}$ signaling was involved in carcinogenesis [24]. Luciferase reporter analysis results validate that NF- $\kappa \mathrm{B}$ plays critical roles in regulating the transcription activity of PPAR $\delta$. CoIP, immunofluorescence and confocal laser scanning microscope assays displayed that HBXIP and NF- $\kappa$ B could bind to each other in the cells, indicating that HBXIP up-regulates the expression of PPAR $\delta$ via NF- $\kappa \mathrm{B}$. Thus, HBXIP functioned as a co-activator of NF- $\mathrm{KB}$ activates PPAR $\delta$ transcription. These findings are consistent with our previous report that HBXIP may function as a co-activator $[4,29]$. Previous studies indicated that PPAR $\delta$ negatively regulated the transcription of NF- $\kappa \mathrm{B}$, such as in inflammation [30] or in diabetic nephropathy [31]. Interestingly, we observed that $\operatorname{PPAR} \delta$ up-regulated the expression of NF- $\kappa \mathrm{B}$ through activating its transcription activity. One possible explanation is that the mechanisms by which PPAR $\delta$ regulates NF- $\kappa$ B in inflammation might be different from that in colonic cancer. Thus, HBXIP accelerated the expression of PPAR $\delta / N F-\kappa B$ feedback loop in the cells. In function, MTT, EdU and colony formation data demonstrated that HBXIP enhanced the proliferation of colonic cancer cells in PPAR $\delta$-dependent manner. In clinical colonic cancer samples, we detected the relationship between HBXIP and clinicopathologic parameters in colonic cancer patients. Interestingly, we found that HBXIP is positively correlated with the lymph node metastasis and advanced TNM stage, suggesting HBXIP expression is positively correlated with the development and progression of colonic carcinoma.

In summary, we show a model that the oncoprotein HBXIP promotes the proliferation of colonic cancer cells via activating PPAR $\delta$, in which HBXIP, functioned as a co-activator of NF- $\kappa \mathrm{B}$, up-regulated the expression of PPAR $\delta$, and the PPAR $\delta$ conversely up-regulated the expression of $\mathrm{NF}-\kappa \mathrm{B}$ through activating its transcription activity (Supplementary Figure 5). The HBXIP/PPAR $\delta$ / $\mathrm{NF}-\kappa \mathrm{B}$ signaling may be a critical key driver in the development and progression of colonic carcinogenesis. Our findings provide new insights into the mechanism by which HBXIP promoted the proliferation of colonic cancer cells. Additionally, HBXIP may serve as a potential biomarker or drug target for diagnosis and treatment for colonic cancer patients.

\section{MATERIALS AND METHODS}

\section{Clinical specimen collection}

A total of 148 colonic carcinoma paraffin-embedded specimen were obtained from patients who underwent surgical resection at the Changzhou Wujin People's Hospital. This study was approved by the Human Ethics Committee board of Changzhou Wujin People's Hospital and informed consent was obtained from patients prior to the research commencing with no patients receiving preoperative treatments. The information of patients with colonic cancer is presented in Supplementary Table 1, which was tested by quantitative real-time PCR, and 83 cases from the 148 colonic carcinoma paraffin-embedded specimens were detected by immunohistochemistry assays. The documented clinicopathological characteristics were: Age, Gender, Tumor size, Differentiation, Lymph node metastasis and TNM stage.

\section{Cell culture and treatment}

Colonic cancer cell line SW480 and HT-29 cells and HEK293T cells were cultured in Dulbecco's Modified Eagle Medium, DMEM (Gibco by life technologies), with 10\% Fetal Bovine Serum (FBS) supplemented with $100 \mathrm{U} / \mathrm{ml}$ penicillin, $100 \mathrm{U} / \mathrm{ml}$ streptomycin and $1 \%$ glutamine at $37^{\circ} \mathrm{C}$ with $5 \% \mathrm{CO} 2$. Transfections were performed by transfecting plasmids pCMV-Tag2B, pCMV-HBXIP or pCMV-p65 into colonic cancer SW480 or HT-29 cells with TurboFect Transfection Reagent (Thermo Scientific). Cells 
were collected and seeded in 6-well, 24-well or 96-well plates for $24 \mathrm{hr}$ and then were transfected with plasmids or siRNAs. All transfections were performed with TurboFect Transfection Reagent according to (Thermo Scientific) manufacturer's instructions. The siRNAs used in our study were as follows: negative control siRNA (si-Control), HBXIP siRNA (si-HBXIP), p65 siRNA (si-p65) and PPAR $\delta$ siRNA (si-PPAR $\delta$ ) (Shanghai GenePharma Co., Ltd).

\section{RT-PCR, qRT-PCR and Western blotting assays}

The total RNA of paraffin-embedded specimens was extracted by using the Recover All Total Nucleic Acid Isolation Optimized for FFPE Sample Kit (Ambion Inc., Texas, USA) following the manufacturer's protocol [32]. And the total RNA from the cells was extracted using Trizol (Invitrogen) according to the manufacturer's protocol. For HBXIP, PPARD and P65 mRNA level detection, the total RNA from colonic cancer SW480, HT-29 cells or from the paraffin-embedded carcinoma specimens were directly reverse transcribed. The qRTPCR was performed as described in the method of SYBR Premix Ex Tag Kit (TaKaRa, Japan). All primers used in this study are listed in Supplementary Table 2. Western blotting was performed as previously described [33]. The primary antibodies used in this study were rabbit polyclonal anti-HBXIP, anti-PPAR $\delta$, anti-p65 (BBI, Sangon Biotech) and anti- $\beta$-actin (Santa Cruz Biotechnology, Santa Cruz, CA).

\section{Immunohistochemistry}

Immunohistochemistry assay was performed as described previously [33]. The slides provided by Pathology of Changzhou Wujin People's Hospital were incubated with rabbit anti-HBXIP (or rabbit anti- PPAR $\delta$ ) antibody at $4^{\circ} \mathrm{C}$ for overnight. After incubation at room temperature for $30 \mathrm{~min}$ with biotinylated secondary antibody, the slides were stained with the 3-amino-9ethylcarbazole according to the protocol of AEC substrate staining Kit (Solarbio).

\section{Plasmids construction}

The 5'-flanking region (from -1491 to -239 nt) of PPAR $\delta$ gene was cloned into the KpnI/MluI site of promoterless luciferase construct pGL3-Basic vector, -1491/-239 (pGL3-1253) (Promega). Then, the recombinant plasmid pGL3-1253 was used as the template to clone the rest of the truncated promoter region, -1296/-239 (pGL3-1058), -1079/-239 (pGL3841), -835/-239 (pGL3-597), -599/-239 (pGL3-361) and $-389 /-239$ (pGL3-151) of PPAR $\delta$ with the same KpnI/ MluI site of the pGL3-Basic vector, respectively. All primers are listed in Supplementary Table 2.

\section{Co-immunoprecipitation (Co-IP) assay}

The co-immunoprecipitation protocol was described in detail on our previously published paper [4]. SW480 cells $\left(2 \times 10^{6}\right)$ were harvested and lysed in a lysis buffer (50 mM Tris- $\mathrm{HCl}$ pH 7.5, 150 mM NaCl, 1 mM EDTA, $0.3 \%$ Triton $\mathrm{X}-100,1 \mathrm{mM}$ protease inhibitor PMSF). The lysates were incubated with antibodies at $4^{\circ} \mathrm{C}$ overnight, next added the pre-washed protein A-conjugated agarose beads at $4^{\circ} \mathrm{C}$ for $2 \mathrm{~h}$. The precipitates were washed eight times with ice-cold lysis buffer, resuspended in the PBS and resolved by SDS-PAGE followed by western blotting.

\section{Luciferase reporter gene assay}

Adherent cells (SW480 and HT-29 cells) were seeded into 24-well plates and, respectively, transfected with the constructs containing different length fragments of PPAR $\delta$ promoter or pGL3-Basic as a negative control, with the pRL-TK plasmid (Promega, Madison, WI) which was used as internal normalization. Cell extracts were harvested after 36 hours and lysed using lysis buffer (Promega). Luciferase reporter gene assay was measured using the GLOMA MULTI DETECTION SYSTEM (Promega) as previously described [4]. All experiments were performed at least three times.

\section{Chromatin immunoprecipitation (ChIP) assays}

The chromatin immunoprecipitation assays were performed by the published methods [34], and the detailed procedures were carried out according to the protocol of the EZ-Magna ChIPTM A-Chromatin Immunoprecipitation Kit (Merck Millipore). Protein-DNA complexes were immunoprecipitated with HBXIP antibodies and with mouse IgG as a negative control antibody. DNA collected by these antibodies was subjected to PCR analysis, followed by sequencing. Amplification of soluble chromatin prior to immunoprecipitation was used as an input control.

\section{Analysis of cell proliferation}

SW480 and HT-29 cells were seeded respectively onto 96 well plates ( 800 cells/well) for $24 \mathrm{~h}$ before transfection and the 3-(4,5-dimethylthiazol2-yl) 22, 5-diphenyltetrazolium bromide (MTT) (Sigma) assays [4] were used to assess cell proliferation every day from the $24 \mathrm{~h}$ until the $96 \mathrm{~h}$ after transfection. In addition, 5-ethynyl-2 0 -deoxyuridine (EdU) incorporation assay was carried out to assess cell proliferation using the CellLight TM EdU imaging detecting kit according to the manufacturer's instructions (RiboBio, China) as well. For the colony formation assays, approximately 1000 SW480 transfected cells or 3000 HT29 transfected cells were placed in six-well plates after $36 \mathrm{~h}$ transfection and maintained in complete medium for 10 days, respectively. 
The colonies were fixed by methanol for $20 \mathrm{~min}$ then stained with methylene blue for $30 \mathrm{~min}$, washed with water and take pictures as previous described [4].

\section{Statistical analysis}

Each experiment was repeated at least three times. Statistical significance was assessed by comparing mean values ( $\pm \mathrm{SD}$ ) using a Student's $t$-test for independent groups and was assumed for $p<0.05\left(^{*}\right), p<0.01\left(^{* *}\right)$ and $p<$ $\left.0.001{ }^{* * *}\right)$. Correlation between expression levels of HBXIP and PPAR $\delta$ in tumor tissues was explored using Pearson's correlation coefficient by the Statistical Analysis System (GraphPad Prism 6, GraphPad Software Inc, CA, USA)

\section{ACKNOWLEDGMENTS}

The authors would like to thank all the members of Department of Pathology of the Changzhou Wujin People's Hospital.

\section{CONFLICTS OF INTEREST}

There are no conflicts of interest to disclose.

\section{FUNDING}

The work was supported by the funds of Changzhou Sci \& Tech Program, Grant No. CJ20160003 and CJ20179002; by Wujin Sci \& Tech Program, Grant No. WS201601 and WS201606; by Changzhou High-Level Medical Talents Training Project, Grant No. 2016CZBJ060 and 2016CZBJ054; Changzhou Health \& Family Planning Commission Program, Grant No. ZD201608, and by Innovative and Entrepreneurial Ph.D funds of Jiangsu Province.

\section{REFERENCES}

1. Ferlay J, Soerjomataram I, Dikshit R, Eser S, Mathers C, Rebelo M, Parkin DM, Forman D, Bray F. Cancer incidence and mortality worldwide: sources, methods and major patterns in GLOBOCAN 2012. Int J Cancer . 2015; 136:E359-386.

2. Bar-Peled L, Schweitzer LD, Zoncu R, Sabatini DM. Ragulator is a GEF for the rag GTPases that signal amino acid levels to mTORC1. Cell. 2012; 150:1196-1208.

3. Melegari M, Scaglioni PP, Wands JR. Cloning and characterization of a novel hepatitis $\mathrm{B}$ virus $\mathrm{x}$ binding protein that inhibits viral replication. J Virol. 1998; 72:1737-1743.

4. Liu Q, Bai X, Li H, Zhang Y, Zhao Y, Zhang X, Ye L. The oncoprotein HBXIP upregulates Lin28B via activating TF II $\mathrm{D}$ to promote proliferation of breast cancer cells. Int J Canc Prev. 2013; 133:1310-1322.

5. Wang Y, Cai X, Zhang S, Cui M, Liu F, Sun B, Zhang W, Zhang X, Ye L. HBXIP up-regulates ACSL1 through activating transcriptional factor $\mathrm{Sp} 1$ in breast cancer. Biochem Biophys Res Commun. 2017; 484:565-571.

6. Yue L, Li L, Liu F, Hu N, Zhang W, Bai X, Li Y, Zhang Y, Fu L, Zhang X, Ye L. The oncoprotein HBXIP activates transcriptional coregulatory protein $\mathrm{LMO} 4$ via $\mathrm{Sp} 1$ to promote proliferation of breast cancer cells. Carcinogenesis. 2013; 34:927-935.

7. Hall MG, Quignodon L, Desvergne B. Peroxisome Proliferator-Activated Receptor beta/delta in the Brain: Facts and Hypothesis. PPAR Res. 2008; 2008:780452.

8. Gou Q, Gong X, Jin J, Shi J, Hou Y. Peroxisome proliferator-activated receptors (PPARs) are potential drug targets for cancer therapy. Oncotarget. 2017; 8:6070460709. https://doi.org/10.18632/oncotarget.19610.

9. Rosenson RS, Wright RS, Farkouh M, Plutzky J. Modulating peroxisome proliferator-activated receptors for therapeutic benefit? Biology, clinical experience, and future prospects. Am Heart J. 2012; 164:672-680.

10. Heck BE, Park JJ, Makani V, Kim EC, Kim DH. PPARdelta agonist with mesenchymal stem cells induces type II collagen-producing chondrocytes in human arthritic synovial fluid. Cell Transplant. 2017.

11. Abd El-Haleim EA, Bahgat AK, Saleh S. Effects of combined PPAR-gamma and PPAR-alpha agonist therapy on fructose induced NASH in rats: Modulation of gene expression. Eur J Pharmacol. 2016; 773:59-70.

12. Hall MG, Quignodon L, Desvergne B. Peroxisome Proliferator-Activated Receptor beta/delta in the Brain: Facts and Hypothesis. PPAR research. 2008; $2008: 780452$.

13. Crunkhorn S. Huntington disease: Boosting PPARdelta blocks neurodegeneration. Nature reviews Drug discovery. 2016; 15:83.

14. Zhang W, Xu Y, Xu Q, Shi H, Shi J, Hou Y. PPARdelta promotes tumor progression via activation of Glut1 and SLC1-A5 transcription. Carcinogenesis. 2017.

15. Angione AR, Jiang C, Pan D, Wang YX, Kuang S. PPARdelta regulates satellite cell proliferation and skeletal muscle regeneration. Skeletal muscle. 2011; 1:33.

16. Ji MJ, Yu XB, Mei ZL, An YQ, Tang SS, Hu M, Long Y, Miao MX, Hu QH, Sun HB, Kong LY, Hong H. Hippocampal PPARdelta Overexpression or Activation Represses Stress-Induced Depressive Behaviors and Enhances Neurogenesis. Int J Neuropsychopharmacol. $2015 ; 19$.

17. Gupta RA, Tan J, Krause WF, Geraci MW, Willson TM, Dey SK, DuBois RN. Prostacyclin-mediated activation of peroxisome proliferator-activated receptor delta in colorectal cancer. Proc Natl Acad Sci U S A. 2000; 97:13275-13280.

18. Zuo X, Peng Z, Moussalli MJ, Morris JS, Broaddus RR, Fischer SM, Shureiqi I. Targeted genetic disruption of peroxisome proliferator-activated receptor-delta and 
colonic tumorigenesis. J Natl Cancer Inst Monogr. 2009; 101:762-767.

19. He TC, Chan TA, Vogelstein B, Kinzler KW. PPARdelta is an APC-regulated target of nonsteroidal anti-inflammatory drugs. Cell. 1999; 99:335-345.

20. Jeong E, Koo JE, Yeon SH, Kwak MK, Hwang DH, Lee JY. PPARdelta deficiency disrupts hypoxia-mediated tumorigenic potential of colon cancer cells. Mol Carcinog. 2014; 53:926-937.

21. Wang D, DuBois RN. PPARdelta and PGE2 signaling pathways communicate and connect inflammation to colorectal cancer. Inflamm Cell Signal. 2014; 1.

22. Wang Y, Sun J, Li N, Che S, Jin T, Liu S, Lin Z. HBXIP overexpression is correlated with the clinical features and survival outcome of ovarian cancer. J Ovarian Res. 2017; 10:26.

23. Wang Y, Fang R, Cui M, Zhang W, Bai X, Wang H, Liu B, Zhang X, Ye L. The oncoprotein HBXIP up-regulates YAP through activation of transcription factor $\mathrm{c}-\mathrm{Myb}$ to promote growth of liver cancer. Cancer Lett. 2017; 385:234-242.

24. Shen HM, Tergaonkar V. NFkappaB signaling in carcinogenesis and as a potential molecular target for cancer therapy. Apoptosis. 2009; 14:348-363.

25. Marusawa H, Matsuzawa S, Welsh K, Zou H, Armstrong R, Tamm I, Reed JC. HBXIP functions as a cofactor of survivin in apoptosis suppression. EMBO J. 2003; 22:2729-2740.

26. You M, Yuan S, Shi J, Hou Y. PPARdelta signaling regulates colorectal cancer. Curr Pharm Des. 2015; 21:2956-2959.

27. Liu S, Li L, Zhang Y, Zhang Y, Zhao Y, You X, Lin Z, Zhang $\mathrm{X}$, Ye L. The oncoprotein HBXIP uses two pathways to up-regulate S100A4 in promotion of growth and migration of breast cancer cells. J Biol Chem. 2012; 287:30228-30239.
28. Liu F, Zhang W, You X, Liu Y, Li Y, Wang Z, Wang Y, Zhang X, Ye L. The oncoprotein HBXIP promotes glucose metabolism reprogramming via downregulating $\mathrm{SCO} 2$ and PDHA1 in breast cancer. Oncotarget. 2015; 6:27199-27213. https://doi.org/10.18632/oncotarget.4508.

29. Liu F, You X, Wang Y, Liu Q, Liu Y, Zhang S, Chen L, Zhang X, Ye L. The oncoprotein HBXIP enhances angiogenesis and growth of breast cancer through modulating FGF8 and VEGF. Carcinogenesis. 2014; 35:1144-1153.

30. Schnegg CI, Kooshki M, Hsu FC, Sui G, Robbins ME. PPARdelta prevents radiation-induced proinflammatory responses in microglia via transrepression of NF-kappaB and inhibition of the PKCalpha/MEK1/2/ERK1/2/AP-1 pathway. Free Radic Biol Med. 2012; 52:1734-1743.

31. Liang YJ, Jian JH, Liu YC, Juang SJ, Shyu KG, Lai LP, Wang BW, Leu JG. Advanced glycation end productsinduced apoptosis attenuated by PPARdelta activation and epigallocatechin gallate through NF-kappaB pathway in human embryonic kidney cells and human mesangial cells. Diabetes Metab Res Rev. 2010; 26:406-416.

32. Gouveia GR, Ferreira SC, Ferreira JE, Siqueira SA, Pereira J. Comparison of two methods of RNA extraction from formalin-fixed paraffin-embedded tissue specimens. Biomed Res Int. 2014; 2014:151724.

33. Gao J, Liu Q, Xu Y, Gong X, Zhang R, Zhou C, Su Z, Jin J, Shi H, Shi J, Hou Y. PPARalpha induces cell apoptosis by destructing Bcl2. Oncotarget. 2015; 6:44635-44642. https:// doi.org/10.18632/oncotarget.5988.

34. Nelson JD, Denisenko O, Bomsztyk K. Protocol for the fast chromatin immunoprecipitation (ChIP) method. Nat Protoc. 2006; 1:179-185. 